\title{
A Vivaldi Antenna with Improved Bandwidth and Gain
}

Original Scientific Papers

\author{
Mohamed Elhefnawy \\ October 6 University, \\ Faculty of Engineering, Dept. of Electrical Engineering \\ Egypt \\ mmmelhefnawy.eng@o6u.edu.eg
}

\section{Frank Podd}

University of Manchester,

School of Electrical and Electronic Engineering

United Kingdom

frank.podd@manchester.ac.uk

\begin{abstract}
In this paper, the radiation characteristics of the conventional Vivaldi antenna are improved by proposing a novel design of a Vivaldi antenna. This proposed Vivaldi antenna is excited through three slots by using the L-probe microstrip feeder. The novel design can provide higher gain and wider bandwidth compared to that of the conventional Vivaldi antenna of the same size. The CSTMWS software is used to simulate the proposed Vivaldi antenna. The measured and the simulated S-parameters were compared so that the feasibility of the proposed Vivaldi antenna was validated. The measured S-parameters show that the impedance bandwidth of the proposed Vivaldi antenna was from 1.976 to $7.728 \mathrm{GHz}$, while the measured maximum gain is $4.9 \mathrm{dBi}$ at the operating frequency of $3 \mathrm{GHz}$.
\end{abstract}

Keywords: Vivaldi antenna, Ultra-Wide Band (UWB), tapered slot antenna, traveling wave antennas

\section{INTRODUCTION}

The Vivaldi antenna was widely studied because of its Ultra-Wide Band (UWB), high gain, end-fire beam with low side lobes, and simple structure. The Vivaldi antenna is used in many applications, such as radar systems, microwave imaging, and wireless communication systems $[1,2,3,4,5,6,7,8]$. A tapered slot is etched onto a thin metal film on a substrate to form tapered slot antenna (TSA), the Vivaldi antenna can be classified as a TSA with an exponential taper. TSA belongs to the class of traveling wave antennas [9]. The structure of the conventional Vivaldi antenna consists of the circular slot, the rectangular slot, and the exponential tapered slot. The circular slot can tune the impedance of the antenna to be matched with that of the microstrip feed line. The Electromagnetic wave is coupled from the microstrip feed line to the exponential tapered slot line through the rectangular slot. The required value of the characteristic impedance of the rectangular slot is achieved by changing the width of this slot. This exponential tapered slot provides the guiding path for the radiating Electromagnetic wave. The bandwidth and the directivity of the Vivaldi antenna depend on the exponential function which is used to design the taper of the slot. The length of the exponential tapered slot controls the achievable bandwidth, while the maximum separation between the conductors of the exponential tapered slot determines the lowest operating frequency. The width of the flare is increased with distance from the throat of the antenna feed. The design of the Vivaldi antenna can be divided into the propagation section and the radiation section. In the propagation section, the electromagnetic wave is propagating from feed line to the rectangular slot. The separation between the conductors of the rectangular slot is small compared to the free-space wavelength, thus the waves will not be radiated. Then the electromagnetic waves travel down the curve path of the flare along the structure of the antenna through the radiation section. In this region, the separation between the conductors is increased and waves will be radiated from the antenna. The radiation will be started when this separation is widened to the order of the free space half wavelength. A Vivaldi antenna comprising of two adjacent Vivaldi exponential tapered slots with a rotated angle of $29^{\circ}$ between them was introduced in [5]. This Vivaldi antenna covers a frequency range from 0.7 to $2.7 \mathrm{GHz}$, and a peak gain of $8.3 \mathrm{~dB}$ can be obtained. In [10], a rhomboid shape for the slot cavity is selected to be used with the Vivaldi antenna. This Vivaldi antenna provides a return loss better than $10 \mathrm{~dB}$ in the band between 3 and $5 \mathrm{GHz}$, and maximum gain of $5 \mathrm{~dB}$. An antipodal Vivaldi antenna with exponential tapered slots and slot edges was 
presented in [11], this antenna operates at a frequency band from $300 \mathrm{MHz}$ to $2 \mathrm{GHz}$, and can provide a maximum gain of $11.5 \mathrm{~dB}$. In $[12,13]$, a Vivaldi antenna with a double-slot structure was introduced to improve the gain by generating plane-like waves across the exponential tapered slot. The obtained bandwidth is from 2.5 to $15 \mathrm{GHz}$, and a maximum gain of $14.5 \mathrm{~dB}$ can be achieved. In [14], a Vivaldi antenna with semicircular embedment is proposed to increase the bandwidth. This Vivaldi antenna has two bands, from 2.96 to 5.05 $\mathrm{GHz}$ and from 5.58 to $8.52 \mathrm{GHz}$. The maximum gain of 5 $\mathrm{dB}$ can be obtained in the band of $2.96-5.05 \mathrm{GHz}$, while a maximum gain of about $6.5 \mathrm{~dB}$ can be achieved in the band of 5.58-8.52 GHz. In [15], an antipodal Vivaldi antenna with elliptically tapered radiators is presented to provide a bandwidth of $1.65-18 \mathrm{GHz}$. In this paper, the proposed novel Vivaldi antenna provides a higher gain than that of the conventional Vivaldi antenna of the same size. The improvement of the antenna gain is achieved by using the three-slot structure, which makes the aperture field distribution in the radiation section more uniform and yields plane-like wavefronts. In addition, the use of the three-slot structure improves the matching between the microstrip feeder and the slotline so that a wider bandwidth can be achieved. The proposed Vivaldi antenna has a higher bandwidth than the obtained bandwidth in [5], [10, 11] and [14]. Also, the proposed Vivaldi antenna can reduce the antenna size by $23 \%$ and $162.3 \%$ compared to those in $[12,13]$ and in [15], respectively. Table 1 indicates the comparison between these different UWB Vivaldi antennas. This paper is organized as follows: Section 2 describes the antenna configuration. Section 3 presents the results and Section 4 concludes the paper.

Table 1. Comparison between different UWB Vivaldi antennas.

\begin{tabular}{|c|c|c|c|c|c|}
\hline Ref & Antenna Substrate & Antenna Size & Antenna structure & Frequency range & $\begin{array}{l}\text { Max. } \\
\text { gain }\end{array}$ \\
\hline$[5]$ & $\begin{array}{l}\text { Duroid } 5880 \text { with permittivity of } \\
2.2 \text { and loss tangent of } 0.004\end{array}$ & $260 \times 254 \mathrm{~mm}^{2}$ & $\begin{array}{l}\text { Vivaldi antenna with two } \\
\text { radiation slots }\end{array}$ & $0.7-2.7 \mathrm{GHz}$ & $8.3 \mathrm{dBi}$ \\
\hline
\end{tabular}

Rogers 4350 with permittivity

\begin{tabular}{|c|c|c|c|c|c|}
\hline [14] & $\begin{array}{l}\text { FR4 } 5880 \text { with permittivity of } \\
5.2 \text { and loss tangent of } 0.038\end{array}$ & $45 \times 40 \mathrm{~mm}^{2}$ & $\begin{array}{c}\text { Semicircular patch } \\
\text { embedded Vivaldi antenna }\end{array}$ & $\begin{array}{l}\text { Band-1: } 2.96-5.05 \mathrm{GHz} . \\
\text { Band-2: } 5.58-8.52 \mathrm{GHz}\end{array}$ & $6.5 \mathrm{dBi}$ \\
\hline [15] & $\begin{array}{c}\text { RO4003C with permittivity } \\
\text { of } 3.38 \text { and loss tangent of } \\
0.0027\end{array}$ & $202 \times 120 \mathrm{~mm}^{2}$ & $\begin{array}{l}\text { Elliptically tapered antipodal } \\
\text { Vivaldi antenna }\end{array}$ & $1.65-18 \mathrm{GHz}$ & $14.2 \mathrm{dBi}$ \\
\hline $\begin{array}{l}\text { Current } \\
\text { work }\end{array}$ & $\begin{array}{l}\text { FR4 with permittivity of } 4.3 \text { and } \\
\text { loss tangent of } 0.02\end{array}$ & $116 \times 79.65 \mathrm{~mm}^{2}$ & $\begin{array}{l}\text { Vivaldi antenna with three } \\
\text { exponential tapered slots }\end{array}$ & $1.976-7.728 \mathrm{GHz}$ & $4.9 \mathrm{dBi}$ \\
\hline
\end{tabular}

\section{ANTENNA CONFIGURATION}

The proposed and the conventional Vivaldi antennas are simulated in CST MWS, and their geometrical configurations are shown in Figures 1 and 2, respectively. Both the antennas have a size of $116 \times 79.65 \mathrm{~mm}^{2}$.
This antenna size was selected in order to get a larger mouth opening so that the value of the lowest frequency of operation can be reduced. The proposed Vivaldi antenna comprises of L-probe microstrip feed line, three circular slots, three rectangular slots and the exponential tapered slot. 


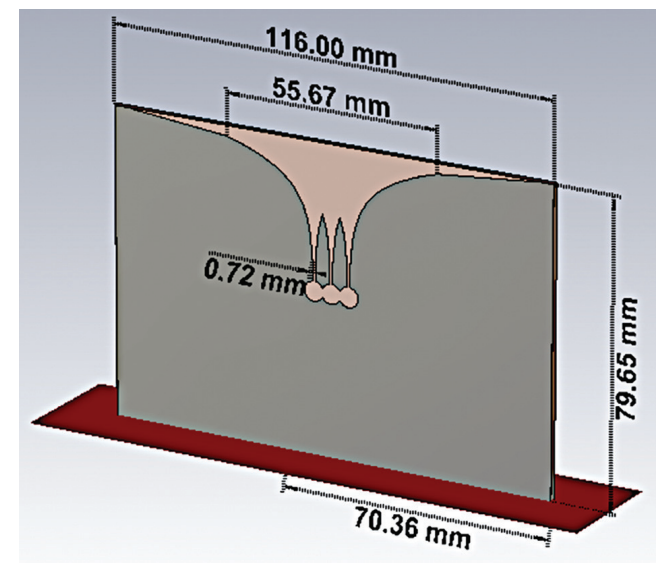

(a)

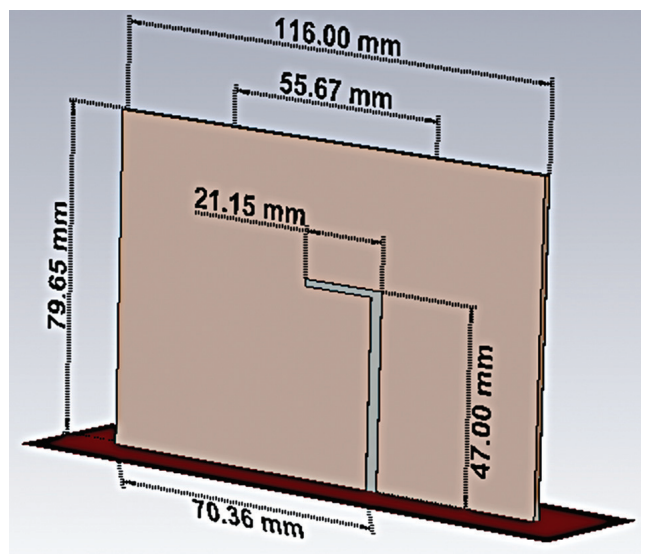

(b)

Fig. 1. Geometry of the simulated proposed Vivaldi antenna (a) front view. (b) back view.

The exponential tapered slot consists of six exponential curves, where the exponential function which is used to design each of these six curves can be deduced by the following equation

$$
x(y)= \pm A e^{R y}
$$

Where $R$ is the exponential taper rate, and $A$ is a constant which was selected to be half the width of the rectangular slot. The value of the exponential tapered slot opening width $\left(w_{a}\right)$ is selected to be greater than $(c /($ $\left.\left.f_{c} \sqrt{\varepsilon_{r}}\right)\right)$ and less than $\left((c(2 M+1)) /\left(2 f_{\min } \sqrt{\varepsilon_{r}}\right)\right)$, where $M$ is a positive number (in this paper, $M=1$ ), $c$ is the speed of light, $\varepsilon_{r}$ is the relative permittivity of the substrate, $f_{c}$ and $f_{\min }$ are the center and the minimum frequencies, respectively $[16,17]$. The width $(W)$ and the length $(L)$ of the Vivaldi antenna are designed based on equations (2) and (3), respectively [17]

$$
\begin{gathered}
W=\frac{c}{f_{\min } \sqrt{\varepsilon_{r}}} \\
L=\frac{(2 N+1) \lambda_{c}}{2 \sqrt{\varepsilon_{e f f}}}-2 \Delta L \\
\varepsilon_{\text {eff }}=\frac{\varepsilon_{r}+1}{2}+\frac{\varepsilon_{r}-1}{2}\left(1+\frac{12 \times h}{W}\right)^{-\frac{1}{2}}
\end{gathered}
$$

$$
\Delta L=0.421 \times h\left(\frac{-0.3-\varepsilon_{e f f}}{0.258-\varepsilon_{e f f}}\right)\left[\frac{0.264+\frac{W}{h}}{0.8+\frac{W}{h}}\right]
$$

Where $h$ and $\varepsilon_{\text {eff }}$ are the thickness and the effective permittivity of the substrate, respectively. $N$ is a positive number (in this work, $N=3$ ), $\lambda_{c}$ is the wavelength at the center frequency and the increased distance on each end along the Vivaldi antenn is denoted by $\Delta L$. The width of the L-probe microstrip feeder $\left(w_{m}\right)$ is obtained as follow [18]

$$
\begin{gathered}
w_{m}=\frac{h \times 8 e^{H_{e}}}{e^{\left(2 H_{e}\right)-2}} \\
H_{e}=\frac{z_{o m} \sqrt{2\left(\varepsilon_{r}+1\right)}}{120}+\frac{1}{2}\left(\frac{\varepsilon_{r}-1}{\varepsilon_{r}+1}\right)\left[\ln \frac{\pi}{2}+\frac{1}{\varepsilon_{r}} \ln \frac{4}{\pi}\right]
\end{gathered}
$$

Where $z_{o m}$ is the characteristic impedance of the L-probe microstrip feeder that was selected to be $50 \Omega$. Also the width of the rectangular slot $\left(w_{s}\right)$ is determined based on the following equation [19]

$$
\begin{gathered}
Z_{\text {os }}=73.6-2.15 \varepsilon_{r}+A+B+C-D \\
A=\left(638.9-31.37 \varepsilon_{r}\right)\left(\frac{w_{S}}{\lambda_{o}}\right)^{0.6} \\
B=\left(36.23 \sqrt{\varepsilon_{r}^{2}+41}-225\right)\left(\frac{W / h}{\frac{W}{h}+0.876 \varepsilon_{r}-2}\right) \\
C=0.51\left(\varepsilon_{r}+2.12\right)\left(\frac{W}{h}\right) \ln \left(\frac{100 h}{\lambda_{o}}\right) \\
D=\frac{0.753 \varepsilon_{r}\left(h / \lambda_{o}\right)}{\sqrt{w_{s} / \lambda_{o}}}
\end{gathered}
$$

Where $\lambda_{o}$ is the free-space wavelength, $z_{o s}$ is the characteristic impedance of the slot line. The exponential taper rate $(R)$ can be calculated as follows [16]

$$
R=1 / L_{a} \ln \left(W / w_{s}\right)
$$

where $\left(L_{a}\right)$ is the length of the exponential tapered slot length. The structure parameters of the proposed and the conventional Vivaldi antennas are listed in Table 2. The front-view of the fabricated sample of the proposed Vivaldi antenna is shown in Figure 3(a). The L-probe microstrip feeder is used to feed the three rectangular slots of the proposed Vivaldi antenna, as shown in Figure 3(b). The lowest frequency of operation is decreased as the mouth opening of the proposed Vivaldi antenna is increased and vice versa. The size of the fabricated antenna can be reduced by increasing the value of the dielectric constant. Gain of the proposed Vivaldi antenna can be increased by selecting a material with a small loss tangent. FR4 dielectric substrate was selected because of its availability and low-cost. The thickness of the FR-4 substrate is $1.6 \mathrm{~mm}$, and its permittivity and loss tangent are 4.3 and 0.02 , respectively. The $50 \Omega$ connector is used to feed the proposed Vivaldi antenna. 


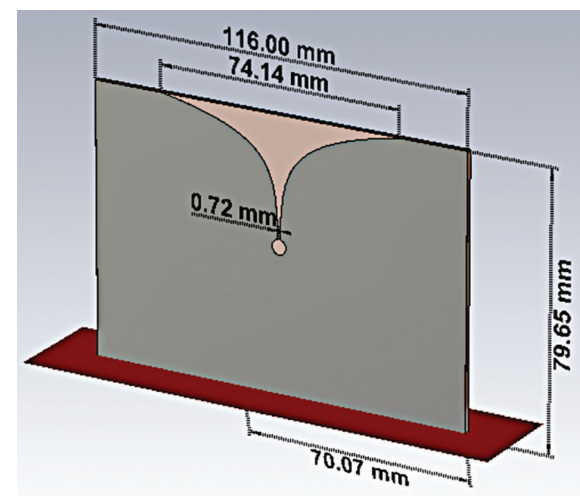

(a)

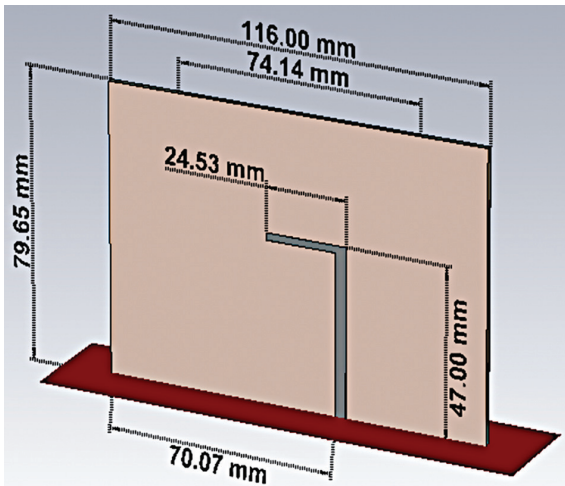

(b)

Fig. 2. Geometry of the simulated conventional Vivaldi antenna (a) front view. (b) back view.

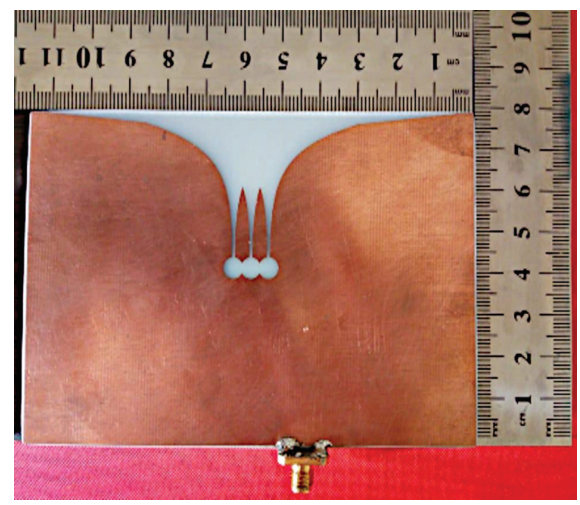

(a)

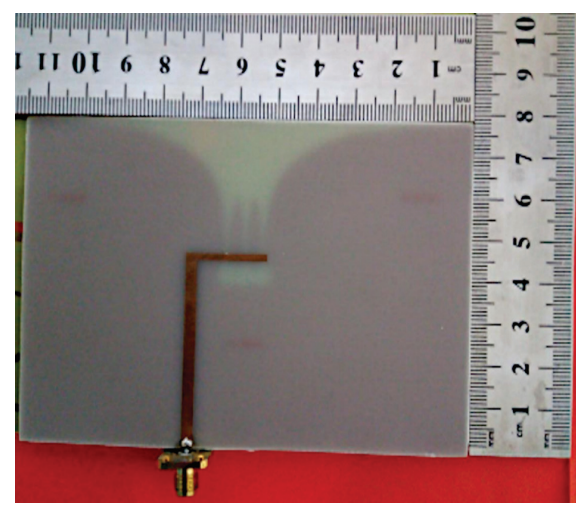

(b)

Fig. 3. Geometrical configuration of the fabricated proposed Vivaldi antenn (a) front view. (b) back view.
Table 2. Structure parameters of the proposed and the conventional Vivaldi antennas.

\begin{tabular}{|c|c|c|}
\hline Parameters & $\begin{array}{l}\text { Dimensions of } \\
\text { proposed Vivaldi } \\
\text { antenna [mm] }\end{array}$ & $\begin{array}{l}\text { Dimensions of } \\
\text { conventional Vivaldi } \\
\text { antenna [mm] }\end{array}$ \\
\hline Antenna length $(L)$ & 116 & 116 \\
\hline Antenna width $(W)$ & 79.65 & 79.65 \\
\hline $\begin{array}{l}\text { Exponential tapered } \\
\text { slot length }(L a)\end{array}$ & 25 & 30 \\
\hline $\begin{array}{l}\text { Exponential tapered slot } \\
\text { opening width (wa) }\end{array}$ & 55.67 & 74.14 \\
\hline $\begin{array}{c}\text { Exponential Taper } \\
\text { rate }(R)\end{array}$ & 0.151825 & 0.151825 \\
\hline $\begin{array}{l}\text { Rectangular slot } \\
\text { length }\end{array}$ & 5.097 & 4.25 \\
\hline $\begin{array}{l}\text { Rectangular slot width } \\
\qquad\left(w_{a}\right)\end{array}$ & 0.72 & 0.72 \\
\hline Circular slot radius & 2.5485 & 2.125 \\
\hline $\begin{array}{l}\text { L-probe microstrip } \\
\text { feeder height }\end{array}$ & 47 & 47 \\
\hline $\begin{array}{l}\text { L-probe microstrip } \\
\text { feeder edge length }\end{array}$ & 21.15 & 24.53 \\
\hline $\begin{array}{l}\text { Width of L-probe } \\
\text { microstrip feeder } \\
\text { height }\left(w_{m}\right)\end{array}$ & 2.8864 & 3.2 \\
\hline $\begin{array}{l}\text { L-probe microstrip } \\
\text { feeder edge width }\end{array}$ & 1.702 & 2 \\
\hline $\begin{array}{l}\text { Length from L-probe } \\
\text { microstrip feeder to } \\
\text { the boarder }\end{array}$ & 70.36 & 70.07 \\
\hline
\end{tabular}

\section{RESULTS}

The CST Microwave Studio software was used to simulate the proposed and the conventional Vivaldi antennas. The antenna parameters such as the S-parameters, the radiation pattern and the gain were examined over a range of frequencies 1 to $9 \mathrm{GHz}$. The Rohde \& Schwarz ZVL vector network analyzer (VNA) was used to measure the fabricated prototype of the proposed Vivaldi antenna as shown in Figure 4.

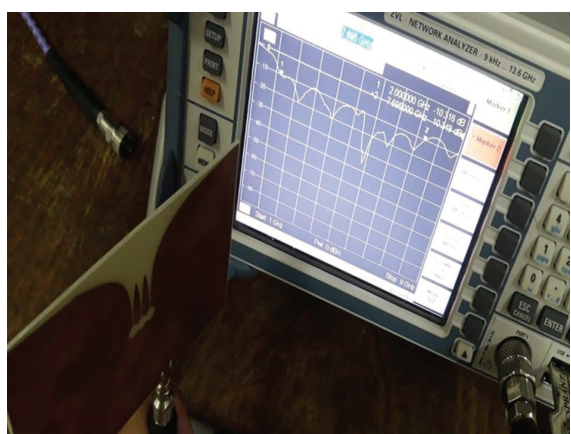

Fig. 4. Measured S-parameters of the fabricated prototype of the proposed Vivaldi antenna

The structure parameters in Table 2 were used to simulate the proposed and the conventional antennas in the CST MWS simulation software. Figure 5 shows the measured and the simulated S-parameters of the proposed Vivaldi antenna, and the simulated S-parameters for the conventional Vivaldi antenna. The measured and the simulated bandwidths of the proposed Vivaldi antenna 
are from 1.976 to $7.728 \mathrm{GHz}$ and from 2.109 to 7.799 $\mathrm{GHz}$, respectively, while the simulated bandwidth of the conventional Vivaldi antenna is from 1.651 to $6.204 \mathrm{GHz}$.

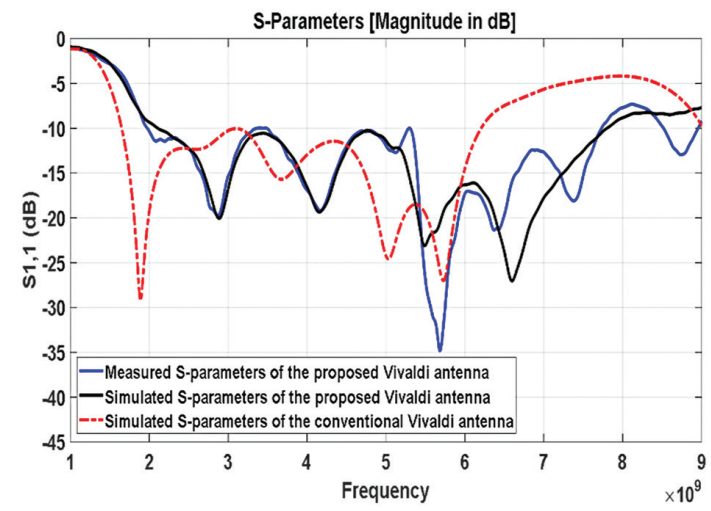

Fig. 5. Measured and simulated S-parameters of the proposed Vivaldi antenna, and simulated S-parameters for the conventional Vivaldi antenna

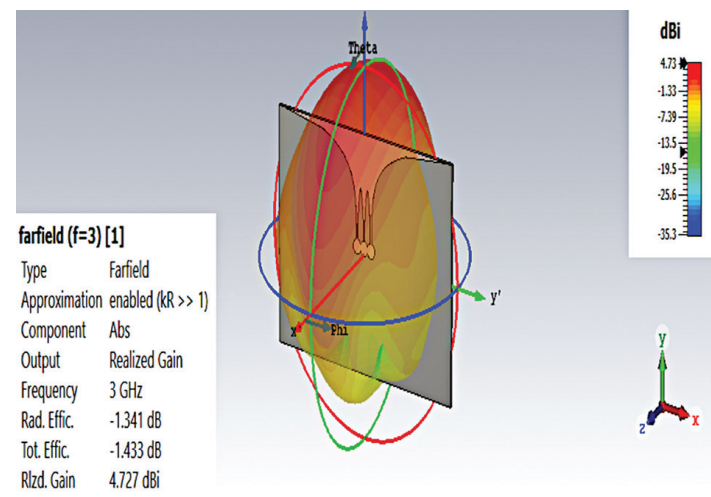

(a)

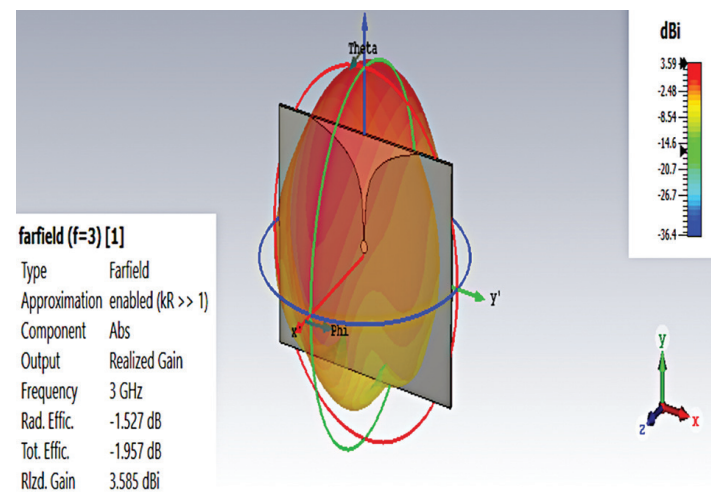

(b)

Fig. 6. 3D radiation pattern at the operating frequency of $3 \mathrm{GHz}$ (a) proposed Vivaldi antennas.

(b) conventional Vivaldi antenna

The $3 \mathrm{D}$ radiation patterns for the proposed and the conventional Vivaldi antennas at the operating frequency of $3 \mathrm{GHz}$ are shown in Figure 6. The proposed Vivaldi structure can provide a radiation pattern with higher gain. Figure 7 shows the measured and the simulated antenna gain versus frequency for the proposed Vivaldi antennas, besides the simulated antenna gain versus frequency for the conventional Vivaldi antenna. For the proposed Vivaldi antenna, the maximum measured antenna gain of $4.9 \mathrm{dBi}$ is achieved at an operating frequency of $3 \mathrm{GHz}$. The measured and simulated results show that the proposed Vivaldi structure can increase the bandwidth by about $25 \%$ compared to the bandwidth of the conventional structure. Except for the frequency band from 4.7 to $5.4 \mathrm{GHz}$, the gain also can be improved by implementing the proposed Vivaldi antenna.

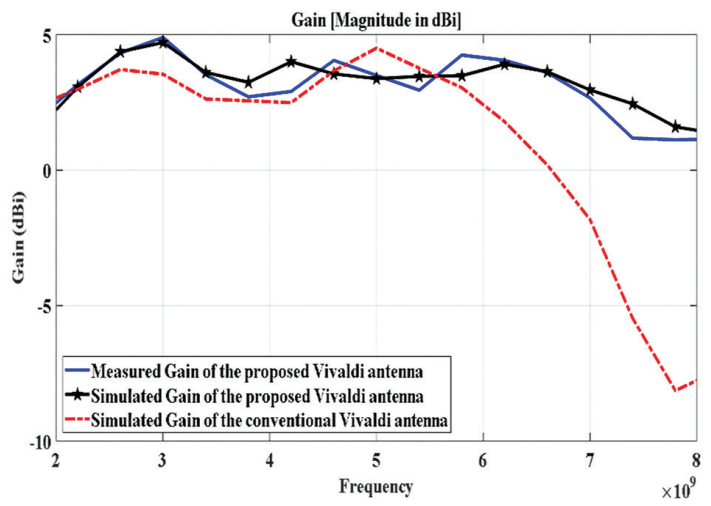

Fig. 7. Measured and simulated gain of the proposed Vivaldi antenna and simulated gain for the conventional Vivaldi antenna

Figure 8 shows that the simulated radiation efficiency is above $70 \%$ for the proposed and the conventional Vivaldi antennas within the frequency range of $2-4 \mathrm{GHz}$. The radiation efficiency of the proposed Vivaldi antenna is equal or higher than that of the conventional Vivaldi antenna, except in the frequency band of $5.1-5.6 \mathrm{GHz}$.

Figure 9 shows the simulated and the measured $\mathrm{E}$ - and $\mathrm{H}$-plane radiation patterns for the proposed Vivaldi antenna at $4 \mathrm{GHz}$. For the simulated and measured E-plane radiation pattern, the direction of the main beam is at $40^{\circ}$, the HPBW of $134.3^{\circ}$ and $120^{\circ}$ in the simulated and the measured E-plane, respectively. The main direction at $3^{\circ}$ is obtained in the simulated and the measured $\mathrm{H}$-plane, while the HPBW of $90^{\circ}$ and $82^{\circ}$ are achieved within the simulated and the measured $\mathrm{H}$-plane, respectively.

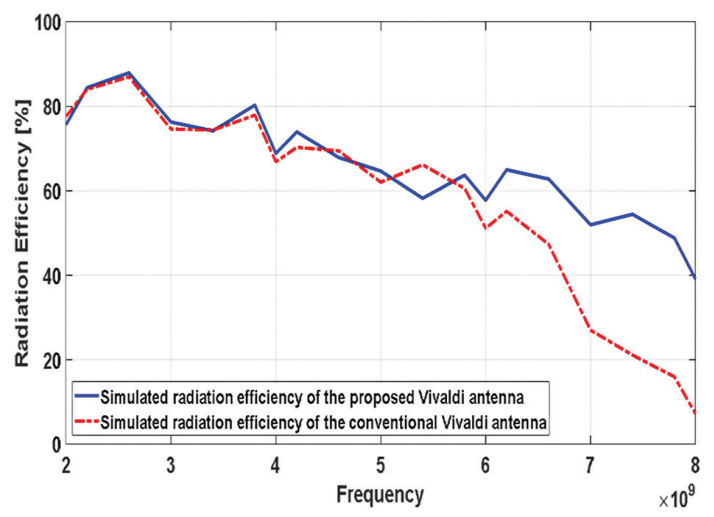

Fig. 8. The simulated radiation efficiency versus frequency for the proposed and the conventional Vivaldi antennas 


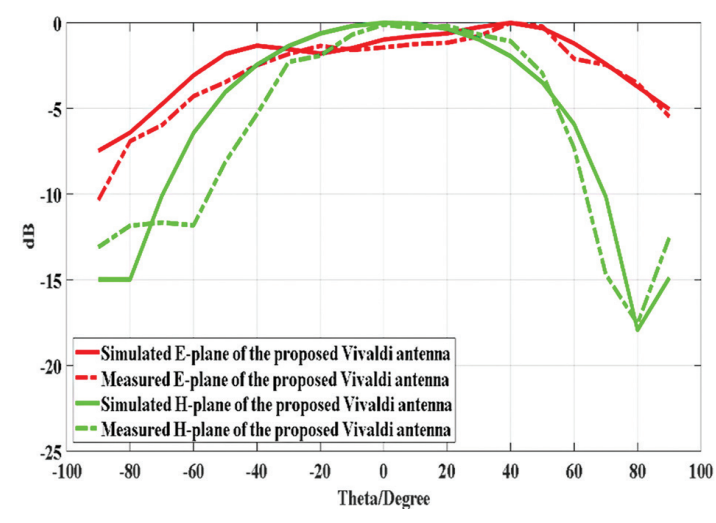

Fig. 9. Simulated and measured E- and H-plane radiation patterns of the proposed Vivaldi antenna

\section{CONCLUSIONS}

A Vivaldi antenna with improved gain and bandwidth is introduced in this paper. This proposed Vivaldi antenna is based on the three-slot feeding structure. The L-probe microstrip is used to excite the three rectangular slots, and the exponential tapered slot of the proposed Vivaldi antenna can generate plane-like waves rather than the spherical-like waves. This proposed Vivaldi antenna is designed based on a mathematical analysis and simulation using CST MWS. The proposed antenna structure can provide a wide bandwidth with smaller antenna size compared to other UWB Vivaldi antennas. The obtained gain is improved by using the proposed Vivaldi antenna. The simulated and the measured results show that the proposed Vivaldi antenna works well in the frequency range of 1.976 to $7.728 \mathrm{GHz}$, and its bandwidth is increased by $25 \%$ compared to the conventional Vivaldi antenna of the same size. The radiation efficiency of the proposed Vivaldi antenna is higher than that of the conventional Vivaldi antenna. Based on the measured and the simulation results, this proposed Vivaldi antenna provides a wide beamwidth. This proposed Vivaldi antenna can be an excellent candidate for many applications, such as radar and wireless communication systems.

\section{REFERENCES:}

[1] W. Wiesbeck, G. Adamiuk, C. Sturm, "Basic Properties and Design Principles of UWB Antennasr", Proceedings of the IEEE, Vol. 97, No. 2, 2009, pp. 372-385.

[2] J. M. Felício, J. M. Bioucas-Dias, J. R. Costa, C. A. Fernandes, "Antenna Design and Near-Field Characterization for Medical Microwave Imaging Applications", IEEE Transactions on Antennas and Propagation, Vol. 67, No. 7, 2019, pp. 4811-4824.

[3] Y. Yang, Y. Wang, A. E. Fathy, "Design of compact Vivaldi antenna arrays for UWB see through wall applications", Progress In Electromagnetics Research, Vol. 82, 2008, pp. 401-418.
[4] D. Comite, A. Galli, I. Catapano, F. Soldovieri, "The Role of the Antenna Radiation Pattern in the Performance of a Microwave Tomographic Approach for GPR Imaging", IEEE Journal of Selected Topics in Applied Earth Observations and Remote Sensing, Vol. 10, No. 10, 2017, pp. 4337-4347.

[5] Y. Dong, J. Choi, I. Catapano, T. Itoh, "Vivaldi Antenna With Pattern Diversity for 0.7 to $2.7 \mathrm{GHz}$ CelIular Band Applications", IEEE Antennas and Wireless Propagation Letters, Vol. 17, No. 2, 2018, pp. 247-250.

[6] E. W. Reid, L. Ortiz-Balbuena, A. Ghadiri, K. Moez, "A 324-Element Vivaldi Antenna Array for Radio Astronomy Instrumentation", IEEE Transactions on Instrumentation and Measurement, Vol. 61, No. 1, 2012, pp. 241-250.

[7] R. Natarajan, M. Kanagasabai, J. V. George, "Design of an X-band Vivaldi antenna with low radar cross section", IET Microwaves, Antennas Propagation, Vol. 10, No. 6, 2016, pp. 651-655.

[8] J. Schneider, M. Mrnka, J. Gamec, M. Gamcova, Z. Raida, "Vivaldi antenna for RF energy harvesting", Radioengineering, Vol. 25, No. 4, 2016, pp. 666671.

[9] J. H. Choi, T. Itoh, Z. Chen, D. Liu, H. Nakano, X. Qing, T. Zwick, "Beam-scanning leaky-wave antennas", Handbook of antenna technologies, Springer-Verlag, 2016, pp. 1-33.

[10] A. Lazaro, R. Villarino, D. Girbau, “Design of tapered slot Vivaldi antenna for UWB breast cancer detection", Microwave and Optical Technology Letters, Vol. 53, No. 3, 2011, pp. 639-643.

[11] G. Jiyu, T. Jisheng, Z. Qing, J. Jiao, H. Jianjian, M. Chunguang, "An ultrawide band antipodal Vivaldi antenna for airborne GPR application", IEEE Geoscience and Remote Sensing Letters, Vol. 16, No. 10, 2019, pp. 1560-1564.

[12] Y. Wang, G. Wang, X. Gao, C. Zhou, "Double-slot Vivaldi antenna with improved gain", Electronics letters, Vol. 49, No. 18, 2013, pp. 1119-1121.

[13] Y. Wang, G. Wang, B. F. Zong, “Directivity improvement of Vivaldi antenna using double-slot structure", IEEE Antennas and Wireless Propagation Letters, Vol. 12, 2013, pp. 1380-1383. 
[14] J. Seo, J. H. Kim, J. Oh, "Semicircular Patch-Embedded Vivaldi Antenna for Miniaturized UWB Radar Sensors", Sensors, Vol. 20, No. 21, 2020, pp. 5988.

[15] M. Moosazadeh, S. Kharkovsky, Z. Esmati, B. Samali, "UWB elliptically-tapered antipodal Vivaldi antenna for microwave imaging applications", Proceedings of the IEEE-APS Topical Conference on Antennas and Propagation in Wireless, Cairns, QLD, Australia, 19-23 September 2016, pp.102105.

[16] A. B. Constantine, "Antenna theory: analysis and design", $4^{\text {th }}$ Ed. John Wiley \& Sons, 2015.
[17] R. K. Kushwaha, P. Karuppanan, “Design and analysis of Vivaldi antenna with enhanced radiation characteristics for mm-wave and $\mathrm{THz}$ applications", Optical and Quantum Electronics, Vol. 51, No. 9, 2019, pp.1-19.

[18] G. Fang, M. Sato, “Optimization of Vivaldi antenna for demining by GPR", Proceedings of the International Symposium on Antennas and Propagation, 2002, pp. 263-266.

[19] V. Tseng, C. Y. Chang, “Linear tapered slot antenna for ultra-wideband radar sensor: Design consideration and recommendation", Sensors, Vol. 19, No. 5, 2019, pp.1212. 